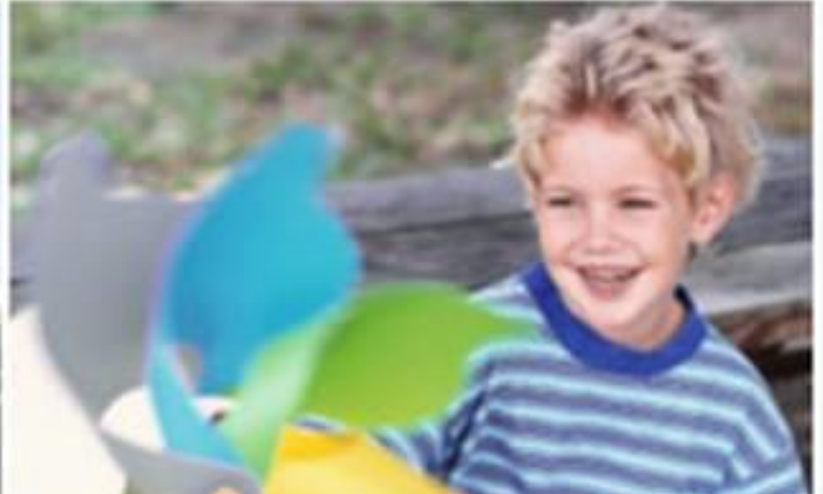

આnigh lo̊poprotein(a)

\title{
Medeiros, $\mathrm{AM}^{1,2}$; Alves, $\mathrm{AC}^{1,2}$; Bourbon, $\mathrm{M}^{1,2}$
}

\begin{tabular}{|c|}
\hline 1.Bıols| \\
\hline
\end{tabular}

${ }^{1}$ Unidade de I\&D, Grupo de Investigação Cardiovascular, Departamento de Promoção da Saúde e Prevenção de Doenças Não Transmissíveis, Instituto Nacional de Saúde Doutor Ricardo Jorge, Lisboa, Portugal

${ }^{2}$ BiolSI - Biosystems \& Integrative Sciences Institute, Faculdade de Ciências, Universidade de Lisboa, Lisboa, Portugal

\section{Aim:}

Familial Hypercholesterolemia (FH) patients have an increased cardiovascular risk due to high TC or LDL-C levels. Lp(a) chemical structure is similar to LDL and elevated $L p(a)$ is considered an independent risk factor for cardiovascular disease (CVD). Recently, it has been described that in patients with high $L p(a)$, the $L p(a)-C$ can contribute up to $25 \%$ to $50 \%$ of all LDL-C. In the present work we aim to determine if elevated $L p(a)$ concentrations can contribute to clinical phenotype of $\mathrm{FH}$.

\section{Mẹthod $15:$}

A cohort of 1374 individuals (875 adults and 499 children) with clinical diagnosis of $\mathrm{FH}$ was analysed. Lipid profile was determined, using an automatic biochemical equipment, by enzymatic colorimetric and immunoturbidimetric methods. Molecular study of $\angle D L R, A P O B$ and PCSK9 genes was performed by PCR and Sanger sequencing. Data was analysed by SPSS using Mann-Whitney and Qui-square tests.

\section{Resulfits:}

The cohort was divided according to the genetic diagnosis in $\mathrm{FH}$ mutation positive $(\mathrm{FHM}+)$, individuals identified with pathogenic or likely pathogenic mutation, and $\mathrm{FH}$ mutation negative (FHM-), individuals without a mutation in $L D L R, A P O B$ and $P C S K 9$ genes.

\section{Children}

- Lp(a) mean levels were statistically significant higher in FHM- when compared with FHM+ (Table 1).

- $33.1 \%$ of children present $\mathrm{Lp}(\mathrm{a})>50 \mathrm{mg} / \mathrm{dL}$ (Figure 1 ).

- In the group of children with $\mathrm{Lp}(\mathrm{a})>50 \mathrm{mg} / \mathrm{dL}, 56.3 \%$ are $\mathrm{FHM}$ - vs $43.7 \%$ $\mathrm{FHM}+(\mathrm{p}<0.001)$ (Figure 1).

Table 1. Lipid profile of children with clinical diagnosis of $\mathrm{FH}$

\begin{tabular}{lccc}
\hline & FHM- & FHM+ & P value \\
\hline TC & $224.7 \pm 36.2$ & $253.0 \pm 51.2$ & $<0.001$ \\
LDL-C & $147.4 \pm 33.3$ & $185.3 \pm 49.0$ & $<0.001$ \\
HDL-C & $60.3 \pm 16.1$ & $50.8 \pm 12.3$ & $<0.001$ \\
TG & $92.0 \pm 46.0$ & $80.7 \pm 41.6$ & $<0.001$ \\
LP(a) & $59.9 \pm 65.7$ & $41.2 \pm 43.4$ & 0.008 \\
APOA1 & $157.9 \pm+30.8$ & $131.8 \pm 22.2$ & $<0.001$ \\
APOB & $97.5 \pm 26.2$ & $122.9 \pm 32.3$ & $<0.001$ \\
\hline
\end{tabular}



Figure 1. Percentage of children with clinical diagnosis of FH presenting elevated levels of $L p(a)$

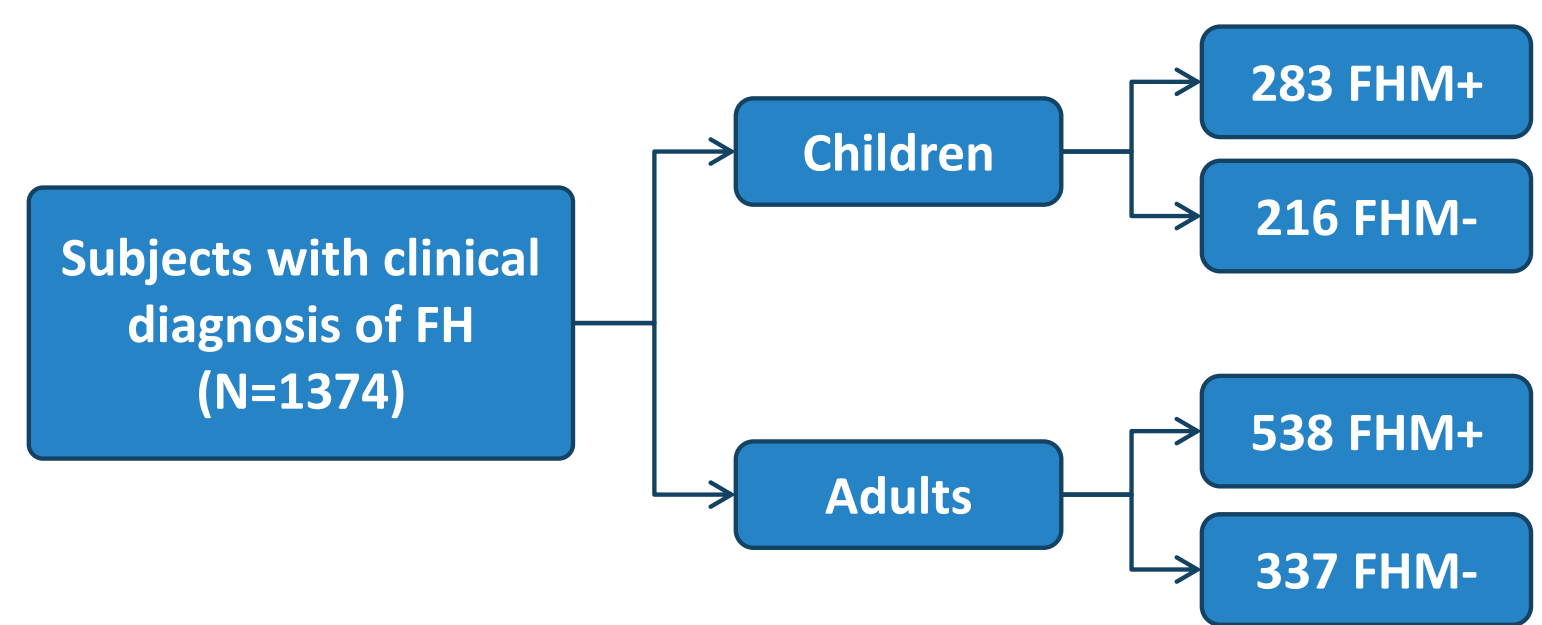

Adults

- $L p(a)$ mean levels were higher in FHM- but not statistically significant $(55.9 \mathrm{mg} / \mathrm{dL}$ vs $52.7 \mathrm{mg} / \mathrm{dL}$ ) (Table 1 ).

- $37.3 \%$ of adults present $L p(a)>50 \mathrm{mg} / \mathrm{dL}$; no statistically significant differences were found between FHM- and FHM+.

- $15.8 \%$ of adults present a premature CVD (mean age 46.3 years).

- In the group of adults with $\mathrm{Lp}(\mathrm{a})<50 \mathrm{mg} / \mathrm{dL} 12 \%$ present $\mathrm{pCVD}$, while $22 \%$ present $p C V D$ in the group of adults with $L p(a)>50 \mathrm{mg} / \mathrm{dL}(p<0.001)$ (Figure 2).

\begin{tabular}{lccc}
\multicolumn{4}{c}{ Table 2. Lipid profile of adults with clinical diagnosis of FH } \\
\hline TC & FHM- & FHM+ & P value \\
\hline LDL-C & $233.7 \pm 66.2$ & $280.2 \pm 75.5$ & $<0.001$ \\
HDL-C & $147.4 \pm 50.9$ & $200.7 \pm+69.8$ & $<0.001$ \\
TG & $56.4 \pm 16.7$ & $53.7 \pm 15.3$ & 0.014 \\
Lp(a) & $172.9 \pm 315.2$ & $126.9 \pm 87.1$ & $<0.001$ \\
APOA1 & $55.9 \pm 61.3$ & $52.7 \pm 58.4$ & 0.959 \\
APOB & $161.3 \pm 35.6$ & $147.4 \pm 31.9$ & $<0.001$ \\
\hline
\end{tabular}

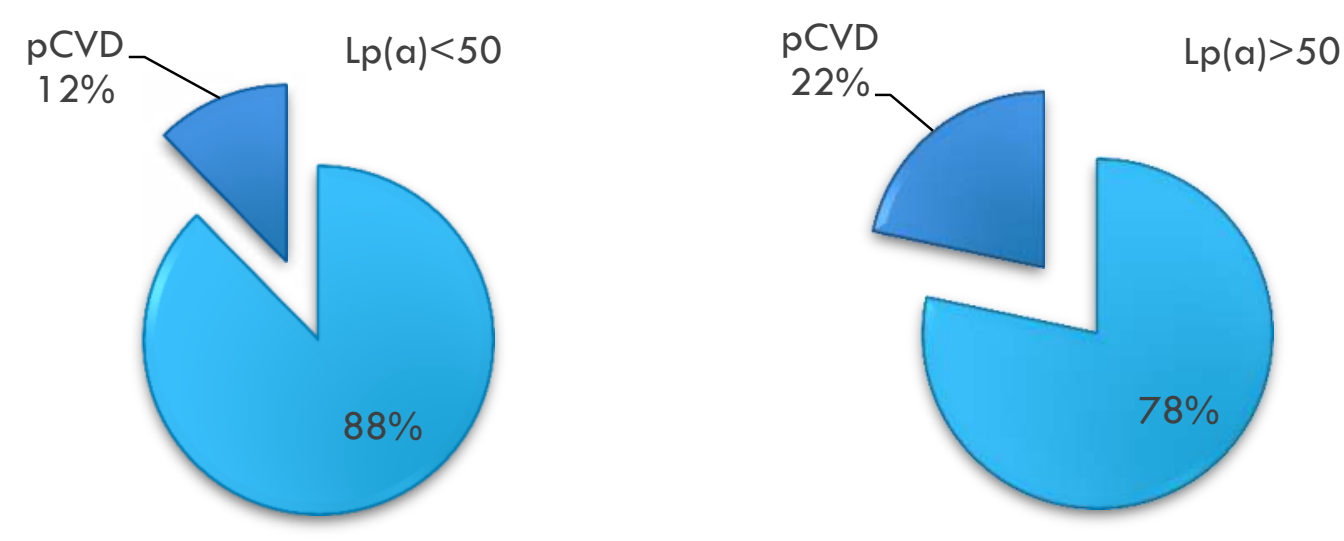

Figure 2. Percentage of adults with clinical diagnosis of FH presenting pCVD divided by low and elevated levels of $\operatorname{Lp}(\mathrm{a})$

\section{Conclusions:}

Almost $50 \%$ of these $\mathrm{FH}$ mutation negative children have $\mathrm{Lp}(\mathrm{a})>50 \mathrm{mg} / \mathrm{dL}$ that can be contributing to elevated LDL-C levels resulting in a $\mathrm{FH}$-like phenotype. Most probably in these cases the genetic cause of their hypercholesterolaemia is not FH but hyper Lp(a).
We've also observed that in the group of adults $37 \%$ present an elevated $\mathrm{Lp}(\mathrm{a})$, that is an additional risk factor to their hypercholesterolemia. Since LDL-C levels of patients with elevated $L p(a)$ cannot be reduced if the $L p(a)$ remains elevated, specific therapies to lower $L p(a)$ are necessary in these patients. 